\begin{tabular}{ccc}
\hline & $\begin{array}{c}\text { International Journal of Health Services, } \\
\text { Research and Policy } \\
\text { www.dergipark.org.tr/ijhsrp }\end{array}$ \\
$\begin{array}{c}\text { INTEREG } \\
\text { ENGINEERINAL } \\
\text { SCIENCE AND } \\
\text { EDUCATION GROUP }\end{array}$ & e-ISSN: $2602-3482$ & IJHSRP \\
\hline Research Article &
\end{tabular}

\title{
EFFECT OF EATING ATTITUDES OF INDIVIDUALS WITH TYPE 2 DIABETES UPON QUALITY OF LIFE
}

\author{
Derya $A k c ̧ a^{1}{ }^{\mathbb{D}}$, Sibel Şentürk ${ }^{* 2} \mathbb{1}$ \\ ${ }^{I}$ Department of Nursing, Istanbul University-Cerrahpasa, Institute of Graduate Students, Florence Nightingale \\ Nursing Faculty, İstanbul, Turkey \\ Department of Nursing, Bucak Health School, Burdur Mehmet Akif Ersoy University, Bucak-Burdur, Turkey \\ *Corresponding author; sibelsenturk@mehmetakif.edu.tr
}

\begin{abstract}
Eating disorders, which are one of the most important causes of poor glycemic control, increase weight gain among diabetic people, complicate weight loss, and reduce the quality of life by aggravating diabetic complications. The current study was undertaken to explore the effect of eating attitudes of individuals with Type 2 diabetes upon the quality of life. This descriptive and cross-sectional study was done with 127 Type 2 diabetic individuals between November 2019 and March 2020. The data were gathered using the Patient Information Form, Eating Attitudes Test, and The Diabetes Quality-of-Life Measure. The average age of the participants was $58.77 \pm 8.78$ years, $62.2 \%$ of them were female and $42.7 \%$ of them showed a cutoff point of $\geq 30$ for eating attitudes. There was a negatively significant correlation between the Type 2 diabetic individuals' total score of eating attitudes test and the sub-dimensions of satisfaction with treatment, the impact of treatment, worries about future effects of diabetes and total diabetes quality of life scores $(r=-.493, p=0.000 ; r=-.226, p=0.011 ; r=-.193$, $p=0.030 ; r=-.390, p=0.000)$ but a positively significant and moderate correlation between the subdimension of worries about social and vocational issues and total score of eating attitudes test $(r=0.304$; $p=0.001)$. It was determined that individuals with Type 2 diabetes with impaired eating behaviors had a low quality of life. It is recommended that with the first diagnosis, individuals' eating behaviors should closely be monitored and they should be informed of the importance of eating and nutrition in diabetes. Keywords: Diabetes mellitus, Type 2, Eating behavior, Quality of life.
\end{abstract}

Received: April 2, 2020 Accepted: May 28, 2020

\section{Introduction}

Diabetes Mellitus (DM) is a metabolic disease characterized by chronic hyperglycemia caused by insulin secretion, insulin activity, or both of them. The most frequently seen diabetes are Type $2 \mathrm{DM}$ (T2DM) - a combination of weak insulin resistance and poor insulin secretion- and Type 1 DM (T1DM) -characterized with insulin secretion deficiency- [1]. According to the report of the International Diabetes Federation (IDF) 2019; the number of people living with DM across the world was nearly 463 million and it is anticipated that the number will have reached over 700 million by 2045 and global DM prevalence will go up gradually. In Turkey; the number of people living with DM is estimated to be nearly 6.5 million and by 2045 the number of diabetic individuals will be almost 10.4 million by putting Turkey among one of the 10 countries where diabetes takes place most [2]. The prevalence of DM and diabetic complications increase morbidity and mortality and decrease quality of life [3,4]. İt is very essential to prevent complications in DM. Complications can be prevented with glycemic control [3]. 
For glycemic control; patients should adopt some lifestyle changes such as healthy eating behaviors, exercise, and weight control [5].

Eating disorders (ED), one of the most crucial causes of poor glycemic control, aggravate weight gain among diabetic people, complicate weight loss, and worsen DM complications [5, 6]. In addition to $\mathrm{ED}$; impaired eating attitudes are among the widest problems of DM patients with poor glycemic control and high BMI and prevalence of ED is reported to change from $12.2 \%$ to $40 \%$ in T2DM individuals [1, 6-8]. Literature also underlines that ED and worsened eating attitudes cause anxiety among DM patients and their quality of life decreases $[1,9]$.

In treating T2DM individuals, eating and nutrition play a key role in preventing disease complications or delaying the emergence of these complications and -therefore- in elevating the quality of life. Therefore, it is necessary to regularly assess symptoms of ED when providing routine care to T2DM individuals [7]. Understanding the correlation between the quality of life, ED and T2DM better will help both health personnel and patients prevent T2DM and will ease the global burden.

The current study was undertaken to explore the effect of eating attitudes of individuals with Type 2 diabetes upon the quality of life.

\section{Materials and Methods}

\subsection{Design and Sample}

This study was conducted descriptive and cross-sectional. The population consisted of the T2DM patients who presented to internal medicine department of a research and training hospital located in northern Turkiye between November 2019 and March 2020 and the sample of the study consisted of 127 T2DM individuals who (a) were aged $\geq 18$ years, (b) were diagnosed with T2DM diagnosis for at least one year (c) took oral anti-diabetic medicines and/or insulin, (d) were not pregnant, (e) did not have communication and perception problems, (f) presented to the internal medicine department for medical examinations during study-period and (g) volunteered to join the study.

\subsection{Data Collection}

Data for the current study were collected by means of Eating Attitudes Test, Diabetes Quality of Life Measure, and a Patient Information Form developed by the researchers following a comprehensive review of the literature [7, 10-13]. After the questionnaire form was prepared, a preliminary interview was held with 5 patients and necessary corrections were made and the investigation started. The questionnaire was collected by researchers using face to face interview technique. Filling in the data collection forms took approximately 35-40 minutes.

\subsubsection{Patient Information Form}

The questionnaire consisted of 16 close-ended questions about the patients' sociodemographic and disease features such as age, gender, Body Mass Index (BMI), Hemoglobin A1c (HbA1c), education status, marital status, work status, income status, diagnosis duration (years), coexisting diseases, treatment type, engaged in diet, hypoglycemia attacks, hyperglycemia attacks, maintaining body weight, being knowledgeable about eating-nutrition. 


\subsubsection{Eating Attitudes Test (EAT)}

The test was developed by Garner and Garfinkel [14] and its Turkish validity and reliability tests were performed by Savaşır and Erol [15]. The test includes 40 questions and responses are in 6 points Likert type "always-never". For the items 1,18,19,23,27 and 39; "sometimes" is marked as 1 point, "rarely" 2 points and "never" 3 points while other options are marked as 0 . For the rest of the items; "always" is marked as 3 points, "very frequently" 2 points, "frequently" 1 point, and other options are marked as 0 points. The total score is determined by adding up the points. The cutoff point for EAT 40 is 30 . Thirty points and above are significant and the level of the total score is directly related to the level of psychopathology. The distinction score for the diagnosis of anorexia was determined to be 30 . Cronbach alpha reliability coefficient was 0.70 in the study of Savaşır and Erol [15]. In this study, the Cronbach alpha reliability coefficient was 0.87 .

\subsubsection{Diabetes Quality of Life Measure (DQOL)}

Original version of the measure, developed in 1970 by Brislin [16], is consisted of four sub-dimensions: satisfaction with treatment (15 items), the impact of treatment (20 items), worries about future effects of diabetes (4 items) and worries about social and vocational issues ( 7 items). The measure is a 5-point Likert type with 46 questions. Scoring is between 1 and 5 points and points marked for each question are summed and the sum is divided by the number of questions. Thus, the average score is obtained. Lower scores indicate a higher quality of life [16]. Turkish validity and reliability tests of DQOL were performed by Yıldırım et al. in 2007 and Turkish adapted version has 45 questions and 4 sub-dimensions [satisfaction with treatment (15 items), the impact of treatment (20 items), worries about future effects of diabetes (4 items), and worries about social and vocational issues ( 7 items)]. Points from 1 to 5 are given to each question and reverse-scoring is used [17]. Cronbach alpha reliability coefficient was 0.89 in the study of Yildirım et al. [17]. In this study, the Cronbach alpha reliability coefficient was 0.78 .

\subsection{Data Analysis}

Statistical analyses of the data were done using SPSS (Statistical Package for the Social Sciences, Chicago, Illinois) 21.0 software. Categorical variables were summarized as numbers and percentages and continuous variables as mean \pm standard deviation (SD). Distributions of the variables were measured by using the Shapiro-Wilk test or Kolmogorov-Smirnov test. Cronbach's alpha value was found using reliability analysis. Independent t-tests were used in two groups which had continuous variables. One-way analysis of variance (ANOVA) was used for more than two groups. Spearman Correlation Analysis was used to determine the relationship between dependent and independent variables. A two-sided $p$-value $<0.05$ was considered significant for all analyses.

Ethical Consideration: Before data collection, Ethics committee approval was gained from the Burdur Mehmet Akif Ersoy University (Decision Date and Number: 04.9.2019; GO 2019/132). The study protocol was conducted according to the Declaration of Helsinki. Written permission was obtained from the Director Office of Hospital. Written consents of the patients, who participated in the study, were obtained after reading an informed consent.

\section{Results}

Average age, BMI, HbA1c and diagnosis duration of the participating T2DM individuals were $58.77 \pm 8.78$ (min: $41-\max : 80$ ), $29.82 \pm 5.65$ (min: 17.4 - $\max : 45.9), 7.67 \pm 1.69$ (min: 5 - max: 13.2) 
and $15.77 \pm 6.33$ (min: 8 - max: 46); respectively. $62.2 \%$ of the participants were female, $59.8 \%$ of them had primary school graduation, $80.3 \%$ of them were married, $16.5 \%$ of them did not work at all and $59.1 \%$ of them had an income equal to expenses. $77.2 \%$ of the T2DM individuals presented another coexisting disease, $41.7 \%$ of them received oral antidiabetic (OAD) treatment, $29.9 \%$ of them were engaged in diets, $5.5 \%$ of them sometimes had hypoglycemia $-7.1 \%$ had hyperglycemia attacks, 26.8 $\%$ of them maintained body weight and only $18.9 \%$ of them were knowledgeable about eating and nutrition in diabetes. Since EAT cutoff was 30; $52.8 \%$ of the participant T2DM individuals showed a cutoff point of $<30$ whereas $42.7 \%$ of them showed a cutoff point of $\geq 30$ (Table 1 ).

Table 1. Distribution of T2DM patients by descriptive characteristics

\begin{tabular}{|c|c|c|}
\hline Descriptive characteristics & $\mathbf{n}$ & $\%$ \\
\hline \multicolumn{3}{|l|}{ Gender } \\
\hline Female & 79 & 62.2 \\
\hline Male & 48 & 37.8 \\
\hline \multicolumn{3}{|l|}{ Education status } \\
\hline Primary school & 76 & 59.8 \\
\hline High school & 27 & 21.3 \\
\hline University graduate & 24 & 18.9 \\
\hline \multicolumn{3}{|l|}{ Marital status } \\
\hline Married & 102 & 80.3 \\
\hline Single & 25 & 19.7 \\
\hline \multicolumn{3}{|l|}{ Work status } \\
\hline Employed & 21 & 16.5 \\
\hline Unemployed & 106 & 83.5 \\
\hline \multicolumn{3}{|l|}{ Income status } \\
\hline Less than expenses & 46 & 36.2 \\
\hline Equal to expenses & 75 & 59.1 \\
\hline More than expenses & 6 & 4.7 \\
\hline \multicolumn{3}{|l|}{ Coexisting diseases } \\
\hline Yes & 98 & 77.2 \\
\hline No & 29 & 22.8 \\
\hline \multicolumn{3}{|l|}{ Treatment type } \\
\hline Diet & 3 & 2.4 \\
\hline OAD & 53 & 41.7 \\
\hline Insulin & 29 & 22.8 \\
\hline OAD+Insulin & 42 & 33.1 \\
\hline \multicolumn{3}{|l|}{ Engaged in diet } \\
\hline Yes & 38 & 29.9 \\
\hline Sometimes & 15 & 11.8 \\
\hline No & 74 & 58.3 \\
\hline \multicolumn{3}{|l|}{ Hypoglycemia attacks } \\
\hline Sometimes & 7 & 5.5 \\
\hline No & 120 & 94.5 \\
\hline \multicolumn{3}{|l|}{ Hyperglycemia attacks } \\
\hline Sometimes & 9 & 7.1 \\
\hline No & 118 & 92.9 \\
\hline \multicolumn{3}{|l|}{ Maintaining body weight } \\
\hline Yes & 34 & 26.8 \\
\hline No & 93 & 73.2 \\
\hline \multicolumn{3}{|c|}{ Being knowledgeable about eating-nutrition } \\
\hline Yes & 24 & 18.9 \\
\hline No & 103 & 81.1 \\
\hline \multicolumn{3}{|l|}{ EAT } \\
\hline$<30$ & 67 & 52.8 \\
\hline$\geq 30$ & 60 & 47.2 \\
\hline Total & 127 & 100.0 \\
\hline
\end{tabular}


As seen in Table 2; among the participant T2DM individuals, there was no statistically significant difference between DQOL sub-dimensions-satisfaction with treatment, the impact of treatment, worries about future effects of diabetes, worries about social and vocational issues and total DQOL score and educational status, marital status, income status, coexisting diseases, treatment type and being knowledgeable about eating-nutrition in diabetes $(p>0.05)$. No statistically significant difference was found in the participant T2DM female individuals' scores of satisfaction with treatment, the impact of treatment, worries about future effects of diabetes and total DQOL scores $(p>0.05)$ whereas female individuals' scores in worries about social and vocational issues were higher as compared to male patients $(p<0.05)$. No statistically significant difference existed between T2DM individuals' employment status and the scores of satisfaction with treatment, the impact of treatment and worries about future effects of diabetes $(p>0.05)$ whereas the employed individuals' scores in worries about social and vocational issues and total DQOL score were higher than those unemployed $(p<0.05)$.

Scores of satisfaction with treatment, the impact of treatment, worries about future effects of diabetes and total DQOL score among those participant T2DM individuals who responded "partly" and "no" to the question about engagement in diets were identified to statistically be higher as compared to those responding "yes" to the same question $(p<0.05)$. There were statistically significant differences between the prevalence of DM individuals' hypoglycemic attacks and scores in the impact of treatment, worries about future effects of diabetes and total DQOL score; between the prevalence of hyperglycemia attacks and scores in the impact of treatment and worries about future effects of diabetes and between maintaining body weight and scores in satisfaction with treatment, the impact of treatment and total DQOL score $(p<0.05)$. Those participant T2DM individuals whose EAT cutoff point was $<30$ demonstrated a higher score in satisfaction with treatment and a higher total DQOL score as compared to those whose cutoff point was $\geq 30$. Those participant T2DM individuals whose EAT cutoff point was $\geq 30$ demonstrated a higher score in worries about social and vocational issues as compared to those whose cutoff point was $<30(p<0.05)$.

Table 2. Comparison of individuals with T2DM with DQOL scale and sub-dimensions

\begin{tabular}{|c|c|c|c|c|c|}
\hline Descriptive characteristics & $\begin{array}{c}\text { Satisfaction } \\
\text { with } \\
\text { treatment }\end{array}$ & $\begin{array}{l}\text { Impact of } \\
\text { treatment }\end{array}$ & $\begin{array}{c}\text { Worries } \\
\text { about the } \\
\text { future effects } \\
\text { of diabetes }\end{array}$ & $\begin{array}{c}\text { Worries } \\
\text { about social } \\
\text { and } \\
\text { vocational } \\
\text { issues }\end{array}$ & $\begin{array}{c}\text { DQOL } \\
\text { Total }\end{array}$ \\
\hline \multicolumn{6}{|l|}{ Gender* } \\
\hline Female & $2.60 \pm 0.43$ & $3.56 \pm 0.45$ & $3.81 \pm 0.48$ & $4.69 \pm 0.12$ & $3.43 \pm 0.29$ \\
\hline Male & $2.65 \pm 0.37$ & $3.52 \pm 0.41$ & $3.85 \pm 0.46$ & $4.58 \pm 0.19$ & $3.42 \pm 0.25$ \\
\hline Test statistics & 2.898 & 0.355 & 0.535 & 22.448 & 1.988 \\
\hline$p$ & 0.485 & 0.613 & 0.695 & 0.001 & 0.812 \\
\hline \multicolumn{6}{|l|}{ Education status** } \\
\hline Primary school & $2.53 \pm 0.39$ & $3.42 \pm 0.41$ & $3.75 \pm 0.45$ & $4.71 \pm 0.12$ & $3.35 \pm 0.26$ \\
\hline High school & $2.73 \pm 0.49$ & $3.63 \pm 0.46$ & $4.00 \pm 0.51$ & $4.71 \pm 0.22$ & $3.40 \pm 0.29$ \\
\hline University graduate & $2.83 \pm 0.32$ & $3.78 \pm 0.45$ & $4.00 \pm 0.51$ & $4.71 \pm 0.17$ & $3.61 \pm 0.29$ \\
\hline Test statistics & 1.820 & 2.890 & 0.965 & 2.128 & 2.213 \\
\hline$p$ & 0.166 & 0.054 & 0.384 & 0.123 & 0.239 \\
\hline \multicolumn{6}{|l|}{ Marital status* } \\
\hline Married & $2.59 \pm 0.39$ & $3.55 \pm 0.45$ & $3.84 \pm 0.47$ & $4.64 \pm 0.17$ & $3.43 \pm 0.28$ \\
\hline Single & $2.70 \pm 0.46$ & $3.50 \pm 0.39$ & $3.79 \pm 0.48$ & $4.66 \pm 0.13$ & $3.44 \pm 0.28$ \\
\hline Test statistics & 1.794 & 0.927 & 0.063 & 1.254 & 0.042 \\
\hline$p$ & 0.226 & 0.623 & 0.621 & 0.723 & 0.825 \\
\hline
\end{tabular}


Table 2. (Continued)

\begin{tabular}{|c|c|c|c|c|c|}
\hline \multicolumn{6}{|l|}{ Work status* } \\
\hline Employed & $2.58 \pm 0.43$ & $3.41 \pm 0.50$ & $3.78 \pm 0.51$ & $4.35 \pm 0.18$ & $3.31 \pm 0.28$ \\
\hline Unemployed & $2.62 \pm 0.40$ & $3.57 \pm 0.42$ & $3.84 \pm 0.47$ & $4.71 \pm 0.06$ & $3.45 \pm 0.27$ \\
\hline Test statistics & 0.124 & 1.252 & 0.017 & 42.497 & 0.051 \\
\hline$p$ & 0.664 & 0.145 & 0.625 & 0.000 & 0.038 \\
\hline \multicolumn{6}{|l|}{ Income status** } \\
\hline Less than expenses & $2.70 \pm 0.38$ & $3.55 \pm 0.43$ & $3.75 \pm 0.39$ & $4.71 \pm 0.12$ & $3.53 \pm 0.27$ \\
\hline Equal to expenses & $2.66 \pm 0.42$ & $3.52 \pm 0.44$ & $4.00 \pm 0.52$ & $4.71 \pm 0.17$ & $3.37 \pm 0.28$ \\
\hline More than expenses & $2.33 \pm 0.32$ & $3.47 \pm 0.46$ & $3.87 \pm 0.51$ & $4.42 \pm 0.21$ & $3.23 \pm 0.29$ \\
\hline Test statistics & 0.910 & 0.216 & 0.024 & 0.914 & 0.922 \\
\hline$p$ & 0.405 & 0.806 & 0.976 & 0.412 & 0.401 \\
\hline \multicolumn{6}{|l|}{ Coexisting diseases* } \\
\hline Yes & $2.63 \pm 0.41$ & $3.54 \pm 0.43$ & $3.85 \pm 0.45$ & $4.66 \pm 0.14$ & $3.44 \pm 0.27$ \\
\hline No & $2.56 \pm 0.40$ & $3.53 \pm 0.46$ & $3.75 \pm 0.56$ & $4.61 \pm 0.20$ & $3.39 \pm 0.29$ \\
\hline Test statistics & 0.030 & 0.047 & 2.108 & 7.782 & 0.022 \\
\hline$p$ & 0.419 & 0.881 & 0.292 & 0.170 & 0.439 \\
\hline \multicolumn{6}{|l|}{ Treatment type*** } \\
\hline Diet & $2.80 \pm 0.21$ & $3.78 \pm 0.69$ & $4.25 \pm 0.80$ & $4.57 \pm 0.21$ & $3.75 \pm 0.40$ \\
\hline OAD & $2.46 \pm 0.42$ & $3.68 \pm 0.39$ & $4.00 \pm 0.48$ & $4.71 \pm 0.16$ & $3.42 \pm 0.29$ \\
\hline Insulin & $2.66 \pm 0.43$ & $3.57 \pm 0.36$ & $3.75 \pm 0.48$ & $4.71 \pm 0.19$ & $3.35 \pm 0.24$ \\
\hline OAD+Insulin & $2.70 \pm 0.37$ & $3.34 \pm 0.48$ & $3.75 \pm 0.42$ & $4.71 \pm 0.13$ & $3.36 \pm 0.29$ \\
\hline Test statistics & 1.617 & 1.825 & 2.123 & 1.107 & 1.037 \\
\hline$p$ & 0.189 & 0.200 & 0.101 & 0.349 & 0.379 \\
\hline \multicolumn{6}{|l|}{ Engaged in diet** } \\
\hline $\mathrm{Yes}^{\mathrm{a}}$ & $2.20 \pm 0.26$ & $3.36 \pm 0.35$ & $3.75 \pm 0.41$ & $4.71 \pm 0.16$ & $3.20 \pm 0.14$ \\
\hline Sometimes ${ }^{b}$ & $2.86 \pm 0.35$ & $3.73 \pm 0.30$ & $3.75 \pm 0.36$ & $4.71 \pm 0.13$ & $3.57 \pm 0.17$ \\
\hline $\mathrm{No}^{\mathrm{c}}$ & $2.86 \pm 0.30$ & $3.57 \pm 0.47$ & $4.00 \pm 0.51$ & $4.71 \pm 0.16$ & $3.57 \pm 0.28$ \\
\hline Test statistics & 57.421 & 4.526 & 3.298 & 2.209 & 26.389 \\
\hline \multirow[t]{2}{*}{$p$} & 0.000 & 0.013 & 0.040 & 0.114 & 0.000 \\
\hline & $\mathbf{b}>\mathbf{a} ; \mathbf{c}>\mathbf{a}$ & $\mathbf{b}>\mathbf{a}, \mathbf{c}>\mathbf{a}$ & $\mathbf{b}>\mathbf{a}, \mathbf{c}>\mathbf{a}$ & & \\
\hline \multicolumn{6}{|c|}{ Hypoglycemia attacks* } \\
\hline Sometimes & $2.73 \pm 0.37$ & $3.12 \pm 0.29$ & $2.89 \pm 0.24$ & $4.63 \pm 0.19$ & $3.20 \pm 0.13$ \\
\hline No & $2.61 \pm 0.41$ & $3.57 \pm 0.43$ & $3.88 \pm 0.42$ & $4.65 \pm 0.16$ & $3.44 \pm 0.28$ \\
\hline Test statistics & 0.832 & 2.333 & 2.732 & 0.949 & 8.623 \\
\hline$p$ & 0.455 & 0.008 & 0.000 & 0.744 & 0.027 \\
\hline \multicolumn{6}{|c|}{ Hyperglycemia attacks* } \\
\hline Sometimes & $2.76 \pm 0.36$ & $3.20 \pm 0.30$ & $3.05 \pm 0.39$ & $4.65 \pm 0.19$ & $3.26 \pm 0.17$ \\
\hline No & $2.61 \pm 0.41$ & $3.57 \pm 0.43$ & $3.89 \pm 0.43$ & $4.65 \pm 0.16$ & $3.44 \pm 0.28$ \\
\hline Test statistics & 0.747 & 1.857 & 0.414 & 0.735 & 5.438 \\
\hline$p$ & 0.333 & 0.015 & 0.000 & 0.975 & 0.059 \\
\hline \multicolumn{6}{|c|}{ Maintaining body weight* } \\
\hline \multicolumn{6}{|l|}{ Yes } \\
\hline \multirow[t]{2}{*}{ No } & $2.20 \pm 0.26$ & $3.39 \pm 0.37$ & $3.69 \pm 0.42$ & $4.60 \pm 0.16$ & $3.21 \pm 0.15$ \\
\hline & $2.77 \pm 0.34$ & $3.60 \pm 0.45$ & $3.88 \pm 0.48$ & $4.66 \pm 0.16$ & $3.51 \pm 0.27$ \\
\hline Test statistics & 2.178 & 3.092 & 0.928 & 1.927 & 21.814 \\
\hline$p$ & 0.000 & 0.021 & 0.056 & 0.072 & 0.000 \\
\hline \multicolumn{6}{|c|}{$\begin{array}{l}\text { Being knowledgeable about } \\
\text { eating-nutrition* }\end{array}$} \\
\hline Yes & $2.67 \pm 0.36$ & $3.57 \pm 0.43$ & $3.82 \pm 0.56$ & $4.67 \pm 0.14$ & $3.46 \pm 0.28$ \\
\hline No & $2.60 \pm 0.42$ & $3.53 \pm 0.44$ & $3.83 \pm 0.45$ & $4.64 \pm 0.16$ & $3.42 \pm 0.28$ \\
\hline Test statistics & 0.232 & 0.699 & 0.369 & 1.195 & 0.032 \\
\hline$p$ & 0.468 & 0.686 & 0.912 & 0.504 & 0.509 \\
\hline \multicolumn{6}{|l|}{ EAT* } \\
\hline$<30$ & $2.73 \pm 0.36$ & $3.61 \pm 0.48$ & $3.88 \pm 0.51$ & $4.60 \pm 0.20$ & $3.49 \pm 0.29$ \\
\hline$\geq 30$ & $2.48 \pm 0.41$ & $3.47 \pm 0.37$ & $3.77 \pm 0.43$ & $4.70 \pm 0.05$ & $3.36 \pm 0.25$ \\
\hline Test statistics & 1.837 & 6.661 & 1.825 & 90.889 & 3.866 \\
\hline$p$ & 0.000 & 0.074 & 0.200 & 0.000 & 0.006 \\
\hline
\end{tabular}

*Independent Sample T Test; **One-way ANOWA 
A positive, significant but weak correlation was found between the participant T2DM individuals' DQOL total score and age $(r=0.232, p=0.009)$ but no correlation was found between EAT total score and age $(r=-.153, p=0.086)$. A negative and moderately significant correlation existed between the participant T2DM individuals' DQOL total score and BMI $(r=-.425, p=0.000)$ whereas a positively and moderately significant correlation was found between EAT total score and BMI $(r=0.326$, $p=0.000$ ). The participant T2DM individuals' DQOL total score and HbAlc were negatively, significantly, and moderately correlated $(\mathrm{r}=-.406, \mathrm{p}=0.000)$ but no correlation was found between EAT total score and $\mathrm{HbA1c}(r=0.060, p=0.506)$. There was not a statistically significant difference between the participant T2DM individuals' DQOL total score, EAT total score, and diagnosis duration $(r=0.079$, $p=0.375 ; r=-.085, p=0.343)$. The participant T2DM individuals' EAT total score and scores in satisfaction with treatment, the impact of treatment, worries about future effects of diabetes subdimensions and total DQOL score were negatively and moderately correlated $(r=-.493, p=0.000 ; r=-$ $.226, p=0.011 ; r=-.193, p=0.030 ; r=-.390, p=0.000$ ) but score in worries about social and vocational issues and EAT total score were positively, significantly and moderately correlated $(r=0.304 ; p=0.001)$ (Table 3).

Table 3. Relationship between some descriptive characteristics of individuals with T2DM and DQOL and EAT

\begin{tabular}{llllllll}
\hline \multicolumn{1}{c}{$\begin{array}{c}\text { Descriptive } \\
\text { characteristics }\end{array}$} & $\begin{array}{c}\text { Satisfaction } \\
\text { with } \\
\text { treatment }\end{array}$ & $\begin{array}{c}\text { Impact of } \\
\text { treatment }\end{array}$ & $\begin{array}{c}\text { Worries } \\
\text { about the } \\
\text { future } \\
\text { effects of } \\
\text { diabetes }\end{array}$ & $\begin{array}{c}\text { Worries about } \\
\text { social and } \\
\text { vocational issues }\end{array}$ & $\begin{array}{c}\text { DQOL } \\
\text { Total }\end{array}$ & EAT \\
\hline Age & $\mathrm{r}$ & $.232^{* *}$ & .036 & $.259^{* *}$ & .158 & $.238^{* *}$ & -.153 \\
& $\mathrm{p}$ & .009 & .692 & $\mathbf{. 0 0 3}$ & .077 & .007 & .086 \\
BMI & $\mathrm{r}$ & $-.425^{* *}$ & $-.474^{* *}$ & $-.237^{* *}$ & $-.274^{* *}$ & .025 &, $326^{* *}$ \\
& $\mathrm{p}$ & $\mathbf{. 0 0 0}$ & $\mathbf{. 0 0 0}$ & $\mathbf{. 0 0 7}$ & $\mathbf{. 0 0 2}$ & .781 & $\mathbf{. 0 0 0}$ \\
HbA1c & $\mathrm{r}$ & $-.406^{* *}$ & .046 & $-.532^{* *}$ & $-.523^{* *}$ & -.001 & .060 \\
& $\mathrm{p}$ & $\mathbf{. 0 0 0}$ & .611 & $\mathbf{. 0 0 0}$ & $\mathbf{. 0 0 0}$ & .990 & .506 \\
Diagnosis & $\mathrm{r}$ & .079 & .080 & .061 & -.007 & .018 & -.085 \\
duration & & & & & & .841 & .343 \\
& $\mathrm{p}$ & .375 & .370 & .498 & .939 & $.304^{* *}$ & 1 \\
EAT & $\mathrm{r}$ & $-.390^{* *}$ & $-.493^{* *}$ & $-.226^{*}$ & $-.193^{*}$ & $\mathbf{. 0 0 1}$ & - \\
\hline
\end{tabular}

$* p<0.05 ; * * p<0.01$ is significant at the level.

\section{Discussion}

Eating attitude disorders that are seen in DM are associated with weak metabolic control, weight gain, tendency not to pay attention to prescribed insulin doses, and increased prevalence in microvascular and macrovascular complications. Therefore, the coexistence of DM and eating attitude disorders causes a high risk for morbidity and mortality as well as a decrease in patients' quality of life [9]. In this sense; in the current study, the effect of T2DM individuals' eating attitudes upon their quality of life was discussed in light of literature. 
Of chronic diseases; T2DM is one of these diseases that physically, socially, and psychologically influence patients' quality of life in terms of both disease outcomes and treatment process. Literature reports a poor quality of life in T2DM individuals $[3,4,13,18]$ and likewise, the current study yielded a low quality of life in T2DM individuals; which may be explained by the fact that DM complications damaging vital organs and nerves lead to life-threatening damages and thus, minimize patients' quality of life [13].

In T2DM individuals, ED is one of the crucial problems that produce insufficient glycemic control and reduce the quality of life. $42.7 \%$ of the participant T2DM individuals demonstrated impaired eating behaviors. The rate of these eating behaviors was reported to be $40 \%$ in the systematic review done by Garcia-Mayor et al. [6], $20 \%$ in the study of Papelbaum et al. [7], 19.6\% in the study of Petroni et al. [11], 12.2\% in the study of Nicolau et al. [8] and 39.3\% in the study of Y1lmaz and Çetinkalp [9]. Such factors as age, gender, metabolic status influence eating attitudes. Therefore; it may be argued that the characteristics of the participants in the current study affected this rate.

T2DM is a chronic disease associated with obesity and metabolic syndrome, and nutrition and eating management and weight control in this disease is a key in treatment as well as prevention. Malmanaged nutrition increases diabetic complications and thus ED deteriorates the quality of life [13]. In the study of Santana et al. [1], it was reported that ED and impaired eating behaviors in DM individuals led to a decrease and an impairment in individuals' quality of life. Cerrelli et al. [19] reported a correlation between disrupted eating behaviors in T2DM individuals and poor quality of life [1, 19]. Similarly; in our study T2DM individuals with impaired eating behavior showed the low quality of life. Parallel to the literature; it may be said that individuals with disrupted eating behavior show poor quality of life.

Female T2DM individuals are one of the groups whose quality of life is negatively affected [10, $13,20]$. In our study; among the T2DM women, only the scores in worries about social and vocational issues were found to be higher than T2DM men and the study of Biyık and Ak1 [21] done to examine DM individuals' quality of life reported results similar to our study. In the current study, the reason why the scores in worries about social and vocational issues were higher in women may be related to the traditional gender roles of women in Turkish society because even if women play an active role in social life and work-life; they equally go on carrying a domestic burden; which appears to raise women's anxiety.

In our study, it was noted that T2DM individuals who were employed had a higher quality of life and similarly, the study of Bilgin et al. [22] on the quality living of T2DM individuals reported that the employed individuals' quality of life was higher. That Almogbel [13] stated a positive effect of employment status in T2DM individuals upon the quality of life concurred with our study finding. When individuals are employed and work in a job where they can have responsibilities, the level of their satisfaction with life goes up and as a result, we are of the opinion that employment status elevates the quality of life.

Nutrition and eating in DM are one of the crucial steps of treatment. The study of Kueh et al. $[12,23]$ reported that those T2DM individuals who were engaged in diets had a better quality of life. Likewise; in our study, those who were engaged in diets showed a higher quality of life as compared to those who were partly engaged in diets or those not engaged in diets at all. Similar to the literature; we may argue that the status of engagement in diets increases the quality of life. 
Hypoglycemia is one of the important disorders in T2DM individuals that may cause physical and psychosocial morbidity. Green et al. [24] found a correlation between T2DM individuals' hypoglycemia and low quality of life. Similarly; Williams et al. [25] identified the negative effects of hypoglycemia of T2DM individuals upon the quality of life. Similar to our study finding, it may be suggested that hypoglycemia causes microvascular complications by influencing T2DM individuals' glycemic control negatively and reduces their quality of life.

In our study, it was concluded that as age increased in T2DM individuals, their quality of life decreased. Likewise; some studies underlined the same correlation between T2DM individuals' age and their quality of life [10, 26-29]. It may be considered that as disease duration lengthens with elevated age, physical functioning is deteriorated and risk for more complications goes up; which may end up with a reduced quality of life. In a healthy population, as age increases, the risk for ED is minimized [30]. Yet, some other studies found no correlation between T2DM individuals' age and their eating disorder, too [1, 8]. Likewise, our study too concluded that age did not affect ED.

Since most of the T2DM individuals are either overweight or obese, the correlation between BMI and quality of life is very important. In our study, it was identified that as BMI increased, quality of life decreased and those who maintained body weight presented a better quality of life. Likewise; in some studies, high BMI values turned out to negatively influence the quality of life [22, 27]. In our study, another dimension that BMI negatively affects is ED. Thus, some studies confirmed that as T2DM individuals' BMI values increase, so do their ED [5, 7, 8, 11]. It may be argued that disrupted eating behaviors are associated with high BMI. We were of the opinion that with increased weight, physical and psychological problems aggravate ED and -as a result- reduce the quality of life.

It is very crucial to keep a balanced and satisfactory glycemic control in life-style diseases like DM. HbA1c is one of the important clinical parameters for assessing glycemic control [28]. There are studies that proved that elevated HbA1c values (> \% 7) lead to low quality of life $[20,27,28]$ and those that suggested no correlation between the quality of life and HbA1c [19]. In our study, high HbA1c was found to be correlated with low quality of life. For us, these differences may result from glycemic control awareness level of the sample groups and HbAlc values indicate a short term glycemic control. In our study, another finding related to $\mathrm{HbA1c}$ was that $\mathrm{HbA1c}$ demonstrated no correlation with impaired eating behaviors. Similarly; the study of Y1lmaz and Cetinkalp [9] found no statistically significant correlation between HbA1c and eating attitudes. However; the study of Papelbaum et al. [7] concluded that T2DM individuals' ED is correlated with weak glycemic control only in the presence of high BMI. Similar to the literature; it may be concluded that HbA1c does not influence eating disorder behaviors.

In our study, it was identified that T2DM individuals' diagnosis duration did not affect the quality of life. Yet, some studies reported that as diagnosis duration increases, quality of life decreases $[13,28]$. This difference between the studies may be explained by the differences in diagnosis duration of the samples. In these studies; diagnosis duration was determined as $<5$ years and $>5$ years. In our study, the minimum diagnosis duration was 8 years and the average diagnosis duration was $15.77 \pm 6.33$ years. It may be suggested that with long diagnosis duration, patients demonstrated a better conformation to and engagement in disease and treatment.

In conclusion, the results of the current study indicated that distorted eating behaviors and low quality of life were widespread in T2DM individuals. Meanwhile, those with impaired eating behaviors presented a low quality of life. According to these results, it is recommended that an assessment of distorted eating behaviors should be realized as a part of the clinical management of T2DM individuals. 
We are of the opinion that in society, it will be helpful to teach proper and well-balanced eating habits, to provide training programs about diabetic eating and nutrition and health services of high quality so that society can adopt regular eating patterns and better quality of life patterns.

\section{Acknowledgments}

The authors would like to thank all the participants.

Ethical Consideration: Before data collection, Ethics committee approval was gained from the Burdur Mehmet Akif Ersoy University (Decision Date and Number: 04.9.2019; GO 2019/132). The study protocol was conducted according to the Declaration of Helsinki. Written permission was obtained from the Director Office of Hospital. Written consents of the patients, who participated in the study, were obtained after reading an informed consent.

The compliance to the Research and Publication Ethics: This study was carried out in accordance with the rules of research and publication ethics.

\section{References}

[1] Dias Santana, D., Mitchison, D., Gonzalez-Chica, D., Touyz, S., Stocks, N., Appolinario, J.C., da Veiga, G.V., Hay, P., "Associations between self-reported diabetes mellitus, disordered eating behaviours, weight/shape overvaluation, and health-related quality of life", Journal of Eating Disorders, 7(35), 1-9, 2019. Doi: 10.1186/s40337-019-0266-y.

[2] International Diabetes Federation, IDF Diabetes Atlas $9^{\text {th }}$ edition, 2019. https://www.diabetesatlas.org/upload/resources/material/20200302_133351_IDFATLAS9e-finalweb.pdf

[3] Vadstrup, E.S., Frølich, A., Perrild, H., Borg, E., Røder, M., "Health-related quality of life and self-related health in patients with type 2 diabetes: Effects of group-based rehabilitation versus individual counseling", Health and Quality of Life Outcomes, 9(110), 1-8, 2011.

Doi:10.1186/1477-7525-9-110.

[4] Zhuang, Y., Ma, Q.H., Pan, C.W., Lu, J., "Health-related quality of life in older Chinese patients with diabetes", Plos One, 15(2), 1-8, 2020. Doi:10.1371/journal.pone.0229652.

[5] García-Mayor, R.V., García-Soidán, F.J., "Eating disorders in type 2 diabetic people: Brief review", Diabetes and Metabolic Syndrome: Clinical Research and Reviews, 11, 221-224, 2017. Doi:10.1016/j.dsx.2016.08.004.

[6] Abbott, S., Dindol, N., Tahrani A.A., Piya, M.K., "Binge eating disorder and night eating syndrome in adults with type 2 diabetes: A systematic review", Journal of Eating Disorders, 6(36), 1-8, 2018. Doi:10.1186/s40337-018-0223-1.

[7] Papelbaum, M., de Oliveira Moreira, R., Coutinho, W.F., Kupfer, R., Freitas, S., Luz, R.R., Appolinario, J.C., "Does binge-eating matter for glycemic control in type 2 diabetes patients?", Journal of Eating Disorders, 7(30), 1-6, 2019. Doi:10.1186/s40337-019-0260-4.

[8] Nicolau, J., Simó, R., Sanchís, P., Ayala, L., Fortuny, R., Zubillaga, I., Masmiquel, L., "Eating disorders are frequent among type 2 diabetic patients and are associated with worse metabolic and psychological outcomes: Results from a cross-sectional study in primary and secondary care settings", Acta Diabetologica, 52, 1037-1044, 2015. Doi:10.1007/s00592-015-0742-z. 
[9] Y1lmaz, M., Cetinkalp, S., "The association of eating attitudes between metabolic control and quality of life in patients with type 1 and type 2 diabetes mellitus", British Journal of Medicine and Medical Research, 13(9), 1-8, 2016. Doi:10.9734/bjmmr/2016/17598.

[10] Jain, V., Shivkumar, S., Gupta, O., "Health-related quality of life (Hr-Qol) in patients with type 2 diabetes mellitus", North American Journal of Medical Sciences, 6(2), 2020. Doi:10.4103/19472714.127752

[11] Petroni, M.L., et al., "Dysfunctional eating in type 2 diabetes mellitus: A multicenter Italian study of socio-demographic and clinical associations", Nutrition, Metabolism and Cardiovascular Diseases, 29(9), 983-990, 2019. Doi:10.1016/j.numecd.2019.06.006.

[12] Kueh Y.C., Morris, T., Ismail, A., "The effect of diabetes knowledge and attitudes on selfmanagement and quality of life among people with type 2 diabetes", Psychology, Health \& Medicine, 22(2), 138-144, 2017. Doi:10.1080/13548506.2016.1147055.

[13] Almogbel, E., "Assessment of health-related quality of life among Saudi patients with type 2 diabetes mellitus in Qassim region-Saudi Arabia", International Journal of Medicine in Developing Countries, 3(11), 1-7, 2019. Doi: 10.24911/IJMDC.51-1568305542.

[14] Garner, D., Garfinkel, P., "The eating attitudes test: an index of the symptoms of anorexia nervosa", Psychological Medicine, 9, 273-279, 1979.

[15] Savaşır, I., Erol, N., "Yeme tutum testi: Anoreksia nervosa belirtiler indeksi", Journal of Psychology, 7(23), 19-25, 1989.

[16] Brislin, R.W., "Back translation for cross-cultural research", Journal of Cross Cultural Psychology, 1(3), 185-216, 1970.

[17] Yildirim, A., Akinci, F., Gozu, H., Sargin, H., Orbay, E., Sargin, M., "Translation, cultural adaptation, cross-validation of the Turkish Diabetes Quality-of-Life (DQOL) measure", Quality of Life Research, 16, 873-879, 2007. Doi:10.1007/s11136-007-9172-x.

[18] Dehvan, F., Saeed, D.M., Dehkordi, A.H., Gheshlagh, R.G., "Quality of life of Iranian patients with type 2 diabetes: A systematic review and meta-analysis", Nursing Practice Today, 6(4), 167 175, 2019. Doi:10.18502/npt.v6i4.1939.

[19] Cerrelli, F., Manini, R., Forlani, G., Baraldi, L., Melchionda, N., Marchesini, G., "Eating behavior affects the quality of life in type 2 diabetes mellitus", Eating and Weight Disorders, 10, 251-257, 2005. Doi:10.1007/BF03327492.

[20] Mohammadi, S., Karim, N.A., Talib, R.A., Amani, R., "Evaluation of quality of life among type 2 diabetes patients", International Journal of Community Medicine and Public Health, 3(1), 5156, 2016. Doi: 10.18203/2394-6040.ijcmph20151485.

[21] Bıyık, S., Ak1, E., Examination of the Relationship between Factors Affecting Activity Performance of People with Diabetes, Master thesis, Hacettepe University, Ankara, Turkey, 2019.

[22] Bilgin, M.S., Özenç, S., Sarı, O., Yeşilkaya, Ş., Aydoğan, Ü., Koc, B., “A study on quality of life in patients with diabetes", Journal of Clinical and Analytical Medicine, 6(2), 159-163, 2015. Doi:10.4328/JCAM.2461. 
[23] Kueh, Y.C., Morris, T., Borkoles, E., Shee, H., "Modelling of diabetes knowledge, attitudes, selfmanagement, and quality of life: A cross-sectional study with an Australian sample", Health and Quality of Life Outcomes, 13(129), 1-11, 2015. Doi:10.1186/s12955-015-0303-8.

[24] Green, A.J., Fox, K.M., Grandy, S., "Self-reported hypoglycemia and impact on the quality of life and depression among adults with type 2 diabetes mellitus", Diabetes Research and Clinical Practice, 96, 313-318, 2012. Doi:10.1016/j.diabres.2012.01.002.

[25] Williams, S.A., Pollack, M.F., Dibonaventura, M., "Effects of hypoglycemia on health-related quality of life, treatment satisfaction and healthcare resource utilization in patients with type 2 diabetes mellitus", Diabetes Research and Clinical Practice, 91, 363-370, 2011.

Doi:10.1016/j.diabres.2010.12.027

[26] Mokhtari, Z., Gheshlagh, R.G., Kurdi, A., "Health-related quality of life in Iranian patients with type 2 diabetes: An updated meta-analysis", Diabetes \& Metabolic Syndrome: Clinical Research \& Reviews, 1-19, 2018. Doi:10.1016/j.dsx.2018.10.007.

[27] Akinci, F., Yildirim, A., Gözü, H., Sargin, H., Orbay, E., Sargin, M., “Assessment of healthrelated quality of life (HRQoL) of patients with type 2 diabetes in Turkey", Diabetes Research and Clinical Practice, 79, 117-123, 2008. Doi:10.1016/j.diabres.2007.07.003.

[28] Al-Maskari, M.Y., Al-Shookri, A.O., Al-Adawi, S.H., Lin, K.G., "Assessment of quality of life in patients with type 2 diabetes mellitus in Oman”, Saudi Medical Journal, 32(12), 1285-1290, 2011.

[29] Luyster, F.S., Dunbar-Jacob, J., "Sleep quality and quality of life in adults with type 2 diabetes", Sleep Quality and Quality of Life, 37(3), 347-355, 2011. Doi:10.1177/0145721711400663.

[30] Hay, P., Mitchison, D., Collado, A.E.L., Gonzalez-Chica, D.A., Stocks, N., Touyz, S., "Burden and health-related quality of life of eating disorders, including Avoidant/Restrictive Food Intake Disorder (ARFID), in the Australian population", Journal of Eating Disorders, 5(21), 1-10, 2017. Doi:10.1186/s40337-017-0149-z. 